\title{
The Influence of Computer Applied Learning Environment on EFL or ESL Education
}

\author{
Rucheng Li \\ Qingdao University of Science and Technology, Qingdao, 266042, China \\ Email: lrctom1212@sina.com
}

\begin{abstract}
Due to the impact and influence of information technology on society and education, more and more colleges or universities start to employ computers for foreign language teaching and learning. Computer applied learning environment has been taken as an ideal way to facilitate second language acquisition in recent years This thesis investigates the effects of a computer-assisted "Fundamental English" course teaching program on the development of English-majors' motivation, learner autonomy, learning strategies and interactive \& cooperative learning in a Chinese context. The roles of teacher in autonomous learning are still under research; as a result, the situation in college English teaching now is a little confusing. On the basis of language output and language test techniques, teachers are playing a more important role in the relation between class-room teaching and autonomous learning-homework-design, and it also proposes some possible teaching techniques and methods, and reveals some significance for effective application of the technology in the Chinese context and points out some limitations of this study.
\end{abstract}

Index Terms - computer applied learning environment, English autonomous learning, new learning concept, interactive \& cooperative learning

\section{INTRODUCTION}

Chinese learners of English always suffer from mastering real, normal and fluent English for lack of a live language environment. To facilitate effective and efficient English learning, we propose an ensemble approach that combines the findings from information technology, linguistics and second language acquisition in order to construct a better English learning environment for Chinese students. In this coming information age, no one can escape from the influence of knowledge explosion. There is no longer a fixed amount of knowledge that can be readily transmitted to learners. Only when learners avail themselves of each learning opportunity to find or create different types of knowledge, and continue life-long learning, can they meet the requirements of the new information age.

However little has been done in the field of English majors' English learning, especially in the reform of "basic English" course which is the trunk course for English majors not to mention empirical studies to investigate learners' changes in the process of development. Main reasons for it are that our state lays more emphasis on the teaching reform of non-English majors' College English learning since it will influence greater numbers of learners' language learning outcome; on the other hand, since the course is the trunk course for first and second year English major students, teachers of this course usually have much work to do during the first year.

Through a combination of both quantitative and qualitative methods, this study explores the changes such a program has brought about in learners' motivation, autonomy, learning strategies, and interactive \& cooperative learning. The underlying factors leading to the changes are also discussed. In other words, it aims to gain a better understanding of the relationship of the CALE to perceived changes in learners' motivation, autonomy, learning strategies as well as interactive \& cooperative learning, so that we can design and implement such programs more effectively in the future.

\section{THE RESEARCH}

Chinese students have long been accustomed to the traditional teaching methods and rigid curriculum. They have been passive learners for many years. Whether they will feel comfortable in the flexible and active learning environment provided by CALE and whether the advocated merits of CALE environment can help them to learn better still remains questionable. In an effort to find the effects of CALE environment on EFL teaching and ESL education in Chinese environment, the writer has conducted an empirical research on 30 freshmen with English as their majors who have undergone a computer assisted most important course (according to the years it has been taught) teaching program implemented in the academic year of 2009-2010 at Hairpin University, China. The study's purpose is to answer the following questions:

1) What are learners' perceptions of the CALE?

2) What impacts does the CALE exert on learners' motivation, autonomy, learning strategies, and interactive learning?

3) What factors enhance or inhibit learner motivation, autonomy, learning strategies, and interactive \& cooperative learning in the CALE? 


\section{A. Context}

Through language foundation training and discourse explanation and analysis, students' discourse reading ability can be improved, their knowledge of various English stylistic expressions and characteristics will be accumulated; meanwhile, their vocabulary will be enlarged, and they will become familiar with frequently used English sentence structures and have fundamental oral and written expression ability.

\section{B. Subjects}

Results of the pre-program survey show the educational and technical background of the subjects. They have been learning English for about 9 to 12 years, with an average of 9.6 years. As English majors of Anhui University which is a key university of the state " 211 " project, all of these students have a very good English foundation since they have achieved high scores in the strict national college entrance examination, with an average of 117 on the subject of English. They are all qualified to take part in the experimental program. Before participating in the program, $46.7 \%$ of these students have never used any operating system or software,

\section{Procedures}

The research was undertaken by the writer teaching College English to Class 1, Grade 2002. The purpose of the experiment which is also a trial reform of the teaching is to provide the participants with an opportunity to practice new electronic literacy through a hands-on way and cooperation with their classmates. They meet in the lab four times a week, two class hours for each time. Also, they regularly have three hours' self-access time every Monday afternoon and sometimes two hours before or after each meeting. During their self-access time, they can complete their course work which has to be done on computer or the Internet, or they can surf on the Internet to practice language competence, or to review teacher's courseware which has been stored on the server.

\section{Data Collection}

As teacher of the class, the writer has designed and observed the whole program. To examine its impacts on learners, both quantitative and qualitative data have been collected through surveys, interviews, records of the students' e-mails and reports as well as the writer's observation notes.

Surveys Two surveys have been administered: Pre-program Survey and Post-program Survey. Both surveys ask similar questions related to learners' motivation, autonomy, learning strategies, and interactive \& cooperative learning etc. Part I of both surveys consists of questions to investigate learners' attitude toward computer and CALE. Part II was designed on the basis of the 4 major influences of CALE environment discussed in Chapter 2, i.e., motivation, learner autonomy, learning strategies, and interactive \& cooperative learning. Influence on motivation is investigated from three motivational factors: communication, empowerment and learning effects; influence on learner autonomy is investigated from three essential elements: goal-setting, independent action and evaluation; influence on learning strategies is investigated from the two non-traditional strategies: information processing and inferring, perception of courseware and learning methods in a CALE classroom; and influence on interactive \& cooperative learning is investigated from five aspects: interdependence, interaction, accountability, interpersonal skills and group processing.

Interview An interview of some open-ended questions has also been conducted. The interview questionnaire is related to students' overall assessment of the program and the benefits and deficiencies as they perceive. The interview questions are as follows: What have you learned from the program? How is the experience different from that in the normal classrooms? Which one do you prefer in your future learning: CALE or traditional way of teaching? What are the special difficulties or problems you have to cope with in this program? If you have a chance to participate in a similar program, what would you suggest for improvement?

Students' Reports Students are supposed to write reports of reflections on the program twice, once in the middle of the program, i.e., the end of the first semester; the other at the end of the program, i.e., the end of the second semester. These reports are authentic data for study.

Researcher's Notes Throughout the whole program, the writer has kept watching the major events, and making notes about them. This is also useful data with which the writer can trace the students' changes when undergoing the program.

\section{E. Data Analysis}

\section{Quantitative Data Analysis}

SPSS is first operated to examine the inside consistency of each category, with the purpose of identifying whether the classification of the twenty-five questions meets the statistical requirement. The value of each question's internal consistency is termed as Alpha. The result indicates that Q13 and Q20 need to be deleted in order to achieve the internal consistency for statistical purpose. After the two questions are deleted, values of the internal consistency of pre-program questionnaire and post-program questionnaire arrive at 0.7139 and 0.9178 respectively, both higher than 0.5 which is the least acceptable value acknowledged by most scholars. SPSS is used to obtain the mean and standard deviation of each item and categories (which is calculated from the mean of every item contained in that category), make paired-sample t-tests with the purpose to see whether there is any statistically significant change for all the subjects in each of the categories. But when typing in the data from the raw material, responses of those negative questions should 
be reverse coded again to ensure the accuracy of questionnaire, i.e., change the original 1 (completely disagree) to 5 (completely agree), 5 to 1, 2 to 4, and 4 to 2. Since the value of 3 does not change, 3 remains unrecorded (Qin, 2003).

The analysis formulas used in the present study are listed as follows (Han, 2000; Qin, 2003):

$$
\begin{array}{ll}
\text { Mean: } & \text { Standard Deviation } \\
\bar{x}=\frac{\sum x}{N} & s=\sqrt{\frac{\sum(x-\bar{x})^{2}}{n-1}}
\end{array}
$$

\section{Qualitative Data Analysis}

Data collection includes the interview transcripts, students' responses, students' reports and researcher's observation notes are considered as raw data. They have experienced the points coding firstly. Then all these key-points extracted from the raw materials are classified into the diversities of motivation, learner autonomy, methodology and interactive $\&$ cooperative learning. Quotations of some of these extracts are taken as proof in this thesis. They are marked heavily inside quotation marks to indicate that they are the original data collected from the students.

\section{FindingS AND DisCUSSIONS}

This chapter presents the results on the research questions mentioned in the previous chapter and the discussions of the reasons underlying the changes. It consists of four sections. The first section reports and discusses changes in motivation in terms of factors of communication, empowerment and learning effect. The second section is devoted to learner autonomy in terms of factors of goal-setting, independent action and evaluation. The third section presents changes in learning strategies. The last section is for interactive \& cooperative learning which is discussed in five sub-sections: interdependence, interaction, accountability, interpersonal skills and group processing. In these sections, changes are presented, alongside discussion of the enhancing and inhibiting factors.

\section{A. Uplifted Motivation}

The research results show that the program has been effective in intriguing learners' interests in language learning and greatly enhanced their self-esteem. Put it in students' own words cited from one of their reports, in a CALL environment,

"We felt active and joyful instead of depressing and insipid. Our enthusiasm for study increased!"

1. Changes in Communication

Mean score of the factor of communication in post-program survey is 4.2167 , which is 1.5667 points higher than that in pre-program survey. Standard deviation drops from .75601 to .70324. The increased mean score indicates that learners' communication with others has been facilitated while the decreased standard deviation suggests variation of learners' perception on this category has become more homogeneous. Result of the $t$-test $(t=-9.560, p=.000)$ shows that the change in this category reached the statistical significant level $(\mathrm{p}<.001)$.

Causes that contribute to this change can be summed up as follows:

In the first place, the long-distance, sometimes even cross-cultural network communication has helped sustain their interests. As a student talked to the writer in the interview,

"I felt so excited when I saw there were responses to my message left on 'Dave's ESL Café'. I value the chance to communicate and exchange opinions with those Indian, German, Australian and many other countries' students."

Then, with the aid of computers and the Internet, learners can publish, revise, move or delete any part of their own language performance conveniently. At the same time, when facing a computer, learners have more time to think and can work at their own pace, their anxiety of being afraid of making mistakes or losing face seems to have reduced to an optimal level.

2. Changes in the Factor of Empowerment

The mean score of changes in the factor of empowerment in the post-program survey is 3.29433, much higher than that in the pre-program survey 2.48333 . The standard deviation drops from .59427 to .51572 . More students tend to agree with each other in this category. Thus, the result of paired samples $t$-test $(\mathrm{t}=-12.801)$ shows the factor of empowerment has undergone a statistically significant change at the level of zero.

There is a computer literacy training phase before the formal implementation of this research. During that period, the subjects are given classes on the Internet search engine, modem database, information retrieval rules and symbols, and some other related technology and skills such as the use of agent server, popular download soft ware's, document styles and so on. After being empowered of efficient knowledge of information retrieval, learners are able to find any information they want on the Internet or in some specific databases.

3. Changes in Learning Effect

The mean score increases by 1.8999 points from 2.2100 before the program to 4.1000 after the program. However, it is out of expectation that the standard deviation increases, which means that learners' perception in this category tends to be more diversified. 
There is left one point for question, i.e., Q5 in this category. Usually, most students' self-esteem and learning motivation have been strengthened by positive learning effects obtained in this study. In their findings, students uniformly claim that they have a great interest in exploring the computer and their confidence have been enhanced for their increased familiarity with computer operation. They absorb knowledge about language as well as other subjects. The Internet broadens their horizon. At the same time, they practice their skills to solve some problems in reality.

\section{B. Improved Learner Autonomy}

\section{Changes in Goal-setting}

The result of the paired samples $\mathrm{t}$-test $(\mathrm{t}=-1.153, \mathrm{P}=.258)$ indicates that the change in this category did not reach the statistical significant level $(\mathrm{P}>.05)$. In other words, students' perception on goal-setting does not change obviously after the program. However, this result is not out of our expectation.

However, upon scrutiny of the statistics, it can still be found that the mean score has increased from 3.8667 in the pre-program survey to 4.0333 in the post-program survey. And the result of the standard deviation decreases greatly from .86037 to .31984 . It is themselves who determined their own focuses on learning. When they take more control over their goals of learning and achieved favorable results of their own decisions, their awareness of setting a definite goal at the beginning of a learning process increases. One of the students expresses it in the interview like this:

"I think it (learning goal) is very important. If you can make arrangements for yourself, you can then carry out your learning plan systematically to achieve this goal. ... without a definite goal, in self-access period in the Internet lab, sometimes we would just wander on the net in great idleness, visiting some websites only for entertainment and killing time."

2. Changes in Independent Action

Great changes have taken place in the element of independent action, since the mean score in the post-program survey is higher than that in the pre-program survey, being improved significantly from 2.3200 to 4.0933 Actually; the training of learners' sense of responsibility has been successful. At the very beginning of the program, some of the subjects feel at a loss when they are told that teacher will no longer occupy the privileged role of sole input of language and linguistic knowledge and they themselves should be responsible for their learning. They are discontent with receiving the confined knowledge arranged for them or being spoon-fed by the teacher. They believe that they should have freedom in choosing learning resources and that is important to the success of their English learning.

\section{SIGNIFICANCE AND CONCLUSION}

As introduced in Part Three, the computer-assisted "Fundamental English" course program is a tentative study, which attempts to explore how English-majors' English learning will be influenced by a CALE in a Chinese context. The results show comparatively satisfying outcomes of the study as well as many implications and limitations.

\section{A. Significance}

1. Supporting Teacher's Preparation

While conducting CALE programs, teachers tend to relinquish some of their power and authority to the students. However, they play an even more important role as guides and coordinators of the learning process. Secondly, most language teachers think the biggest obstacle to implementing CALL is the technology problem. To successfully integrate CALE into language teaching and to be qualified to teach the computer-literacy courses, language teachers themselves should be familiar with basic hardware and software knowledge, the Internet and LAN, and so on; and be capable of developing basic forms of courseware. Thirdly, teachers should offer learners psycho-social support in the CALE environment to spur them on at the moment of uncertainty and support them in their efforts to overcome various obstacles.

2. Improving Students' Inveteracy

Although most students made much progress on many categories, there are still a few who stood still or even refuse to fit into the CALE, or had difficulty in getting rid of certain inveteracy. With regard to this kind of student, the best suggestion is to quit this program temporally to make up for both. Otherwise, not only the computer operation ability can not be improved, but the development of language proficiency will be hindered. Therefore, the inveterate concepts of traditional ways of learning have to be cleared; otherwise, all learners' integrative improvement can never be achieved.

3. Bettering Low-Tech Conditions

Computers and servers are linked and they are connected to the Internet through the campus network, a part of CERNET (China Education and Research Network). One is the unstableness of the Tell How Multimedia Classroom Software 3.0. The other one is the slow network transmission rate. All PCs in the Internet lab have only domestic IP. If the teacher and learners want to visit foreign websites, they have to use agent server, which cause unbearable slow network transmission rate. As we all know, most authentic language materials can only be found on foreign websites. Therefore, the low-tech conditions have to be upgraded in future study.

B. Conclusion 
In the present research, the writer has tried to explore the significance that a CALE program is of to supporting the learners' language learning. The result is that the program has achieved comparatively satisfying outcomes.

To begin with, most students in the study feel more confident and comfortable to join discussion via computer, and they enjoy using computer to communicate in English. What's more, the program has improved the subjects' learner activeness. After the program, the subjects put more emphasis on the setting of a specific and final learning goal. Lastly, the program has enriched the subjects' learning strategies. Since the courseware has helped them to understand the text in a more direct, visual, vivid and even interactive way, the subjects' perceptions of courseware are also significantly improved. In brief the CALE program is perceived by the subjects as a new enjoyable way to learn English effectively.

\section{REFERENCES}

[1] Brookfield, S. D. (1986). Understanding and facilitating adult learning: A comprehensive analysis of principles and effective practices. Buckingham: Open University Press.

[2] Cohen, A. D. (2000). Strategies in learning and using a second language, Beijing: Foreign Language Teaching \& Research Press.

[3] Crystal, D. (1997). English as a global language, Cambridge: Cambridge University Press.

[4] Crystal, D. (2001). Language and the internet, Cambridge: Cambridge University Press.

[5] Dewey, J. (1938). Education and experience, New York: Macmillan.

[6] Dewdney, G. (2000). The internet and the language classroom, Cambridge: Cambridge University Press.

[7] Fosston, C.T. (1996). Constructivism: A psychological theory of learning. In Fosston, C. (Eds.) Constructivism: Theory, perspective and practice (pp. 3-4). New York: Teachers College Press.

[8] Janssen, D. (1999). Learning with technology: A constructive perspective. NJ: Prentice-Hall.

[9] Levy, M. (1997). Computer-assisted language learning: Context and conceptualization, Oxford: Clarendon Press.

[10] Nunan, D. (1995). Language teaching methodology: A textbook for teachers, Hertfordshire: Prentice Hall.

[11] Nunan, D. (2001). The learner-centered curriculum: A study in second language teaching, Cambridge: Cambridge University.

[12] Patton, M. Q. (1990). Qualitative evaluation and research methods, Newbury Park: Sage Publications

[13] Pennington, M. C. (1996). (Ed.) The power of CALL, Houston: Athelstan.

[14] Richards, J. C. (2001). The context of language teaching, Beijing: Foreign Language Teaching \& Research Press.

Rucheng Li was born at Tai' an, China in 1971. He received his B.A. in 1994 and is expected to receive his M.A. in 2012.

$\mathrm{He}$ is currently a lecturer in the School of Foreign Languages, Qingdao University of Science and Technology, Qingdao, China. His research interests include teaching methodology and translation. 